\title{
El Lazarillo de Tormes, Dom Casmurro, ou, o discurso da memória de dois inocentes?
}

\author{
Hugo Jesus Correa Retamar
}

\begin{abstract}
Resumo: Através da leitura comparativa dos livros, escritos em primeira pessoa, El Lazarillo de Tormes (Espanha - Anônimo - 1554) e Dom Casmurro de Machado de Assis (Brasil - 1899), pretende-se analisar o papel do narrador como veículo transformador de uma realidade vivida. Desta forma, faz-se necessário um olhar mais detalhado sobre a construção do discurso de ambos os narradores que se apóiam na memória, re-significada pelo tempo, para reconstruir o passado. Tais relatos se baseiam naquilo que os narradores recordam, mas também no testemunho de outros personagens que falam pela boca do narrador após muitos anos. Logo, pretende-se através deste trabalho discutir a validade de tais discursos permeados pelo tempo, pela necessidade de narrar e pela memória.
\end{abstract}

Palavras-chave: narrador; tempo; narrar; memória.

\begin{abstract}
Through the comparative reading of the books El Lazarillo de Tormes (Spain - Anonymous 1554) and Dom Casmurro by Machado de Assis (Brazil - 1899), both written in first person, it is analysed the role of the narrator as a transforming vehicle of an experienced reality. Therefore, it is needed a detailed look into the discursive strategies of both narrators, founded on memory and re-signified by time, to reconstruct the past. Such stories are based on what the narrators remember, but also on the testimony of other characters who speak through the narrator's voice after many years have passed. Thus, it is intended through this work to discuss the authenticity of such speeches permeated by time, memory and the need of telling.
\end{abstract}

Keywords: narrator; time; narrate; memory.

Lo recuerdo (yo no tengo derecho a pronunciar ese verbo sagrado, sólo un hombre en la tierra tuvo derecho y ese hombre ha muerto.

BORGES, Funes el Memorioso

Ao reler Dom Casmurro de 1899, um clássico da Literatura brasileira que rompeu com tantos pressupostos da Literatura da época no Brasil, uma narrativa em primeira pessoa, já tantas vezes analisada e discutida, não pude deixar de observar determinadas características que, vez por outra em minha leitura, levavam-me a um outro país, a um outro contexto social, a um outro século, porém, de uma forma de narrar semelhante. Logo pude perceber que muito antes de Dom Casmurro, um outro narrador em primeira pessoa, narrador-personagem, já

\footnotetext{
* Hugo Retamar é licenciado em Letras com habilitação em língua espanhola e literaturas de língua espanhola e língua portuguesa e literaturas de língua portuguesa. Foi professor substituto do setor de espanhol da Universidade Federal do Rio Grande do Sul de 2006 a 2008. Têm publicações sobre literatura de língua espanhola e portuguesa, além de ser professor colaborador do Instituto Cervantes de Porto Alegre. Atualmente é estudante de mestrado na área de Literaturas de Língua Espanhola (UFRGS). E-mail: hojarasca@ig.com.br
} 
contava suas peripécias fazendo crítica social, justificando aos outros e a si suas opções no passado. Com o intuito de aproximar as duas obras e os dois narradores em questão - El Lazarillo de Tormes (Anônimo, 1554, Espanha) e Dom Casmurro (Machado de Assis, 1899, Brasil) - disponho-me a percorrê-las e trazer à tona a semelhança de ambos os relatos extremamente realistas e inovadores que revolucionaram a Literatura não apenas de suas épocas e que só se tornaram possíveis graças à memória e à vontade ou à necessidade de contar de um narrador.

Lázaro de Tormes (1554) - o primeiro pícaro da Literatura de língua espanhola, inspirador de tantos outros como Guzmán de Alfarache, Don Pablos, Rinconete y Cortadillo e até de alguns personagens de Don Quijote de la Mancha - é bem como Dom Casmurro, narrador de Machado de Assis, um eu que fala de si. Diz José María Valverde sobre o primeiro romance picaresco:

Un rasgo esencial, y muy "moderno", es que la picacersca se escribe em primera persona, como experiência directa, como supuesta autobiografía, siendo el "yo" lo que unifica episodios sin trabazón argumental, confiriendo a la vez al estilo un nuevo acento directo y una especial radicalidad crítica. (VALVERDE, 1969, p.78)

Um eu que usa sua memória para relatar fatos que justificam sua condição atual. Lázaro nasce dentro do Rio Tormes, que banha Salamanca, na Espanha. Seu nascimento nada tem a ver com o dos cavaleiros medievais tão honrados, tão dignos e tão freqüentes na literatura espanhola da época que consumia, com loucura, o romance de cavalaria. Logo, o livro abre uma nova tradição nesta literatura, a já mencionada picaresca, que não se vale de heróis de nobreza e bravura, nem do maravilhoso, mas que conta com o depoimento do próprio personagem sobre a dureza e realidade crua de sua vida de vagabundo e miserável.

Lazarillo é um menino pobre, praticamente indigente. Órfão de pai, criado por uma mãe que se envolve com um homem que lhes traz comida. Desta relação da mãe, o menino ganha um irmão negro. As condições de vida da família são muito precárias, portanto, a mãe de Lazarillo decide deixá-lo aos cuidados de um cego para que o filho se torne um hombre bueno. Como a mãe, o menino também deve "arrimarse a los buenos" (El Lazarillo de Tormes, 2005, p.25). Ao entregá-lo ao cego, o primeiro de tantos amos, Lazarillo passa a ser uma despesa menos na casa. Diz a mãe de Lazarillo: “- Hijo: ya se que no te veré más. Procura de ser bueno y Dios te guíe. Criado te he y con buen amo te he puesto: válete por ti." [grifo meu] (El Lazarillo de Tormes, 2005, p.27).

Começa assim o processo de aprendizagem de Lazarillo através de cada amo, como é próprio à literatura picaresca. O herói pícaro entra na narrativa em estado de inocência, ou faz 
com que o leitor acredite nesta sua inocência. Aos poucos aprende a safar-se das situações inóspitas através da astúcia que já possui, mas que passa a desenvolver com cada amo. O pícaro percorre a geografia do país através da peregrinação que faz em busca de novos amos, já que sua relação com estes sempre acaba em confusões que o fazem fugir e buscar um novo meio de vida, bem como outra figura que o ensine e o sustente. Lazarillo, também como todo o pícaro, não se adapta a nenhum dos amos e descobre com cada um novos truques de sobrevivência em uma sociedade falida onde ascender socialmente é ter um prato de comida. Com o cego, seu primeiro amo, Lazarillo aprende a ser astuto, já que "el mozo del ciego un punto ha de saber más que el diablo." (El Lazarillo de Tormes, 2005, p.27). Porém o menino desentende-se com o cego, que era, segundo Lazarillo, muito cruel, e este o abandona após uma pequena vingança por parte do jovem aprendiz. O menino, então, parte para uma nova aventura e para um novo amo. Desta vez, um padre com quem tenta usar um pouco da astúcia, descoberta com o cego, para vencer a avareza do sacerdote que não lhe dá de comer. Também têm problemas com o padre e foge mais uma vez descobrindo o terceiro amo, um escudeiro, que culmina sua primeira fase de aprendizagem. O menino passa a viver com o escudeiro que 'parece' ser de boa índole e muito rico. Para Lazarillo é difícil acreditar que sua sorte mudou. Porém, com o passar do tempo, percebe que o escudeiro de bom coração é mais pobre que o próprio Lazarillo. O único bem do qual dispõe este seu novo amo é a roupa que veste que 'parece' ser de uma pessoa de classe. Quer dizer, Lazarillo aprende com este novo amo que, para vencer na sociedade da época, é preciso 'parecer' e não 'ser'. Não é necessário ser uma pessoa honrada, mas 'parecer' uma pessoa honrada através da aparência física. O escudeiro vivia em uma casa vazia de móveis e de comida e o único bem que possuía era sua honra, a dissimulação desta e sua roupa que cuidava com muito aprumo. Assim, Lazarillo passa a viver de esmolas e a sustentar seu amo com elas. Desta vez quem foge é o amo e Lazarillo segue seu caminho de infortúnio rumo a transformar-se em Lázaro de Tormes, o pregoeiro.

Os seguintes amos são consequiências destes três primeiros que lhe deixam os mais importantes ensinamentos, ou seja, o despertar da inocência, a astúcia e a dissimulação. Desta maneira, os próximos amos serão oportunidades para a aplicação do que foi aprendido com os primeiros.

Ao final da narrativa, encontramos um Lázaro de Tormes que é pregoeiro de vinhos e que está casado com uma "tan buena mujer como vive en las puertas de Toledo" ( $E l$

\footnotetext{
${ }^{1}$ Uma clara ironia de Lázaro, já que era de conhecimento de toda Toledo que sua mulher o traía com o arcipreste. Ao falar desta maneira, Lázaro enfatiza a condição de várias esposas toledanas que traíam seus maridos tanto como a sua, mas que aparentemente eram senhoras tão respeitáveis como sua esposa.
} 
Lazarillo de Tormes, 2005, p.78). Quem o casou foi o arcipreste de San Salvador, que visita a casa de Lázaro freqüentemente e de quem coincidentemente sua mulher era criada antes do casamento. Também sabemos pela boca do narrador que o arcipreste trata a mulher de Lázaro com muitos cuidados, quase como uma filha. Porém, quem nos conta toda esta história não é Lazarillo e sim Lázaro de Tormes. Durante toda a narrativa, que se dirige a uma suposta vuestra merced, vemos a transformação de Lazarillo em Lázaro. Uma transformação que passa pela infância (Lazarillo), época da inocência, pela adolescência, época de seu aprendizado, até a idade adulta quando já é Lázaro de Tormes e sabe usar tudo que foi aprendido nas fases anteriores de sua vida; ou seja, quem nos conta a história não é o inocente Lazarillo e, sim, o vivido Lázaro já transformado e distanciado, tanto social como temporalmente do 'puro' menino que nasce no rio Tormes sem perspectivas para seu futuro. E assim é que o experiente e pícaro Lázaro nos conta as misérias do menino e a 'glória' do homem que devem ser acompanhadas desde o princípio para que possamos identificar-nos com os suplícios de Lazarillo e, desta maneira, compreender a Lázaro, o homem que vive com uma mulher adúltera e que dissimula não saber do adultério para não perder a condição social adquirida. É como se Lázaro estivesse diante de um tribunal que o está condenando por sua vida de vícios e sordidez, e ele estivesse se defendendo para convencê-los e convencer-nos de que é inocente de seu destino e de que a culpa de sua condição é do meio e das histórias de vida que teve como exemplo (mãe, pai, cego, padre, escudeiro, etc). A impressão do leitor é de que Lazarillo é um pobre menino vítima de seu destino; porém, será esta a verdade de Lazarillo? Ou a verdade conveniente para Lázaro?

Dom Casmurro (1899) também fala de si. Por suas palavras conhecemos José Dias e seus superlativos, Capitu e sua dissimulação, Escobar e sua facilidade para os cálculos. Ao contrário de Lázaro, Dom Casmurro é um homem de posses, porém, também usa da memória para, de alguma forma, também justificar suas atitudes do passado. Dom Casmurro, bem como Lázaro (que era Lazarillo ao começo da narrativa), começa sua narrativa pela gênese de Bentinho, ou seja, dele mesmo no passado. Sua mãe, seus tios, a história da família e seu primeiro conflito: ir para o seminário. Sua mãe havia prometido que seu filho seria padre e a quebra desta promessa é o motor de toda a primeira parte da narrativa. Para desfazer o juramento da mãe, Bentinho conta com a ajuda de José Dias, astuto agregado da família e, claro, da não menos astuta, segundo a narrativa, Capitu, seu amor da juventude. Bentinho é um rapaz puro e inocente (como diz Lázaro sobre Lazarillo), quase um títere nas mãos de sua mãe, de José Dias e de Capitu. Estes dois espertos personagens conseguem bons estratagemas, e Bentinho é liberado do seminário, porém, lá conhece Escobar, um belo menino que será seu 
amigo íntimo a ponto de provocar o segundo conflito da trama e o fatal desenlace. Bentinho se casa com Capitu, Escobar com Sancha, melhor amiga de Capitu. Bentinho vive o "céu"2 que é o casamento e a amizade com Escobar. Capitu engravida e nasce Ezequiel, que no princípio é uma criança adorável, até que Bentinho passa a desconfiar que este seja filho de Escobar. Sua vida muda radicalmente até que Escobar morre, Bento se separa da mulher, que vai para a Europa com o filho, porém, sempre mantêm as aparências e viaja constantemente à Europa com a desculpa de visitar a família (terá valido a Bentinho o aprendizado de Lazarillo com o escudeiro? Será realmente Capitu a dissimulada da história?). Capitu morre, Ezequiel volta para vê-lo, Bento Santiago o trata seca e friamente. O rapaz também morre, e Bento, já Dom Casmurro, decide escrever um livro para passar o tempo. Seria a História dos subúrbios, mas como precisa "atar as duas pontas da vida e restaurar na velhice a adolescência" (MACHADO DE ASSIS, 1997, p.17) decide escrever sobre si. Nestes moldes, é que vai escrever seu livro baseado em suas memórias, buscando a si. Porém como diz o próprio Bento “da memória, conservo alguma recordação doce e feiticeira” (MACHADO DE ASSIS, 1997, p.17). Logo, será a memória de Bentinho um testemunho fiel de sua juventude? Será Capitu, aquela criada pela memória feiticeira, realmente o retrato fiel da real Capitulina? Será Bentinho tão inocente como nos faz crer Dom Casmurro?

Após esta breve resenha crítica de ambas as obras, passemos à análise dos laços que as unem. As duas narrativas são motivadas pela vontade do $e u$ narrador de escrever e justificarse. Lázaro perante vuestra merced e Dom Casmurro perante ele mesmo que necessita atar os dois pontos da vida e encontrar-se. Logo, o ato de narrar se torna uma possibilidade, para os narradores, de redenção de seus conflitos, sejam eles internos ou externos. Diz María Zambrano sobre o ato de escrever:

Escribir es defender la soledad en que se está; es una acción que sólo brota desde un aislamiento efectivo, pero desde un aislamiento comunicable, en que, precisamente, por la lejanía de toda cosa concreta se hace posible un descubrimiento de relaciones entre ellas. [...] Habiendo un hablar, ¿Por qué escribir? Pero lo inmediato, lo que brota de nuestra espontaneidad, es algo de lo que íntegramente no nos hacemos responsables, porque no brota de la totalidad íntegra de nuestra persona; es una reacción siempre urgente, apremiante. Hablamos porque algo nos apremia y el apremio llega de fuera, de una trampa en que las circunstancias pretenden cazarnos, y la palabra nos libra de ella. Por la palabra nos hacemos libres, libres del momento, de la circunstancia asediante e instantánea. [grifo meu] (ZAMBRANO, 1993, p.31)

Lázaro quer livrar-se, quer fazer com que sua condição de vida seja entendida, ou quer dissimular sua opção de vida, quer dar uma nova interpretação ao 'arrimarse a los buenos' que lhe pede sua mãe. Ao narrar sua vida, ele justifica sua marginalidade e o esforço que fez

\footnotetext{
${ }^{2}$ Refere ao título No Céu do capítulo 101.
} 
para vencer e tornar-se bom como lhe pediu sua mãe, porém, ao reconstruir sua infância, o astuto narrador que, como dito anteriormente, já não é o menino Lazarillo e, sim, o adulto Lázaro, nos apresenta uma nova chave para a interpretação através da caracterização da sociedade espanhola; ou seja, nos faz ver que o conceito de bom (bueno) para aquela sociedade significava simplesmente 'comer' e não importavam os meios utilizados para chegar a este fim. Por este motivo, Lázaro de Tormes se mostra como um vencedor, e não como um vencido. Já Dom Casmurro quer convencer-se e convencer-nos de que sua vida não foi em vão e de que realmente Capitu era culpada de adultério, já que se não fosse ele teria cometido um grande erro que lhe custou a vida e a felicidade. Assim Bento Santiago, Dom Casmurro, se apóia na memória 'feiticeira' e constrói uma Capitu ardilosa através da boca de José Dias e de outras personagens. Ao fazê-lo, o narrador resolve o conflito interior da dúvida. Afinal, não foi ele que pensou mal de Capitu, mas todos que estavam à sua volta, inclusive sua mãe que passou a ter restrições com relação à moça após o casamento. Ao enfatizar a culpa de Capitu, Bento Santiago absolve Bentinho, o menino inocente, ou seja, ele mesmo, do fracasso de sua vida.

Como comentado anteriormente, o conflito tenta resolver-se pela narração, e esta só se faz possível pela manipulação da memória. A memória do narrador não é coletiva, ainda que se apóie no dizer de outros personagens. A seleção dos fatos desta memória narrada, a organização dos mesmos, é fruto de um querer do narrador que busca absolvição pela palavra, pelo ato de confessar, a seu modo, o vivido. Para a absolvição, é necessária a cuidadosa manipulação do que deve ser contado e, claro, uma exposição lógica e coesa daquilo que deve ser contado.

Para desnudar um pouco este mundo do narrador que tem a palavra, comecemos a analisar alguns pontos que organizam e dão crédito à palavra do narrador. Já que o narrador da narrativa de memórias é o criador de um mundo que se desencadeia por ele mesmo, faz-se necessária a "cosmogonia de si mesmo"3. O deus-narrador cria o mundo-personagem, isto é, o próprio narrador só existirá após fazer das trevas a luz. Antes do narrador não há mundo, não há narrativa já que ele é o foco da mesma. Logo, a gênese de Lazarillo e de Bentinho se justifica para torná-los seres de carne e osso para que convençam o leitor. Porém, esta luz que termina com as trevas, que faz com que conheçamos o personagem-mundo, é disseminada pelos próprios olhos deste personagem. Assim, só conhecemos Lazarillo pelos olhos de

\footnotetext{
${ }^{3}$ Nas palavras de Donaldo Schüler em Plenitude Perdida.
} 
Lázaro, isto é, conhecemos o menino inocente e pobre pelos olhos do experiente e astuto adulto Lázaro:

Pues sepa vuestra merced, ante todas cosas, que a mí llaman Lázaro de Tormes, hijo de Tomé González y de Antona Pérez, naturales de Tejares, aldea de Salamanca. Mi nacimiento fue dentro del río Tormes, por la cual causa tomé el sobrenombre, y fue desta manera. Mi padre, que Dios perdone, tenía cargo de proveer una molienda de una aceña que está ribera de aquel río, en la cual fue molinero más de quince años. Y estando mi madre una noche en la aceña, preñada de mí, tomóle el parto y parióme allí. De manera que con verdad me puedo decir nacido en el río. (El Lazarillo de Tormes, 2005, p.25)

Da mesma forma conhecemos Bentinho por Bento, o homem maduro e decepcionado com a vida:

[...] São retratos que valem por originais. O de minha mãe, estendendo a flor ao marido, parece dizer: "Sou toda sua, meu guapo cavalheiro!" O de meu pai, olhando para a gente, faz este comentário: "Vejam como esta moça me quer..." Se padeceram moléstias, não sei, como não sei se tiveram desgostos: era criança e comecei por não ter nascido. Depois da morte dele lembra-me que ela chorou muito; mas aqui estão os retratos de ambos, sem que o encardido do tempo lhes tirasse a primeira expressão. São como fotografias instantâneas da felicidade. (MACHADO DE ASSIS, 1997, p.27)

Os personagens entram em cena somente para dar pistas ou para resolver os conflitos do narrador/personagem. O escudeiro de Lazarillo de Tormes só entra em cena pra ensiná-lo a saber dissimular. José Dias, em Dom Casmurro, entra em cena para ajudá-lo na tarefa de desvincular-se do seminário e para apoiar o juízo negativo sobre Capitu, e a própria Capitu é exemplo de dissimulação e de reforço da inocência de Bentinho, já que se criam assim os opostos (Bentinho/Capitu X Inocência/Astúcia):

[...] Olhos de ressaca? Vá de ressaca. É o que me dá a idéia daquela feição nova. Traziam não sei que fluido misterioso e enérgico, uma força que arrastava para dentro, como a vaga que se retira da praia, nos dias de ressaca. Para não ser arrastado, agarrei-me às outras partes vizinhas, às orelhas, aos braços, aos cabelos espalhados pelos ombros; mas tão depressa buscava as pupilas, a onda que saía delas vinha crescendo, cava e escura, ameaçando envolver-me, puxarme e tragar-me. (Idem p.71)

Porém cabe a pergunta: e se as histórias fossem contadas por dois narradores? Seria Lázaro inocente de seus delitos? Seria Capitu a culpada de adultério? As memórias, ou melhor, a memória, base da narração, é 'fruto de fatos' que marcaram a vida dos protagonistas, porém, não são os 'fatos', mas uma representação destes fatos, alterada por uma série de variáveis como a necessidade de redenção, a visão parcial, a imaginação, o tempo, a necessidade do convencimento, a astúcia do narrador e até os olhos turvos do mesmo que pode não ver com clareza o mundo a sua volta. Então, a memória narrada não é o vivido e, sim, uma representação deste e como toda a representação agrega, subverte, re-acomoda o 
vivido, mesmo porque nosso cérebro não agüentaria guardar todos os fatos vividos ${ }^{4} \mathrm{em}$ sua seqüência estrita. Segundo Donaldo Schüler:

$\mathrm{O}$ vivido se manifesta e se oculta no representado. O representado, ao apresentar o vivido, reveste-o também de uma forma qualitativamente diferente do que era. Na representação, vê-se e não se vê o vivido. (SCHÜLER r, 1978, p.24.)

Ao contar, o narrador que escolhe os argumentos a serem contados, organiza-os de uma maneira bastante plausível, porém, se nos ativermos aos detalhes das entrelinhas, perceberemos que o discurso que quer ser verdadeiro está cheio de contradições e realmente não é, ou não deve ser exatamente o vivido. Surge então um jogo de ocultar e mostrar, de dizer e não dizer já que a memória recompõe o vivido através de rastros ${ }^{5}$. Em ambas as narrativas, as contradições do narrador se mostram nas entrelinhas dos textos. Em Lazarillo de Tormes, Lázaro diz ser um homem sem estudos que alcançou o nível máximo de ascensão social ao ser pregoeiro, porém, no mesmo prólogo da obra, encontramos a eloquiência e a cultura de um homem consciente e letrado que parece não ser o mesmo personagem que é vilipendiado pela sociedade cruel da época que o narrador quer deixar transparecer:

Yo por bien tengo que cosas tan señaladas, y por ventura nunca oídas ni vistas, vengan a noticia de muchos y no se entierren en la sepultura del olvido, pues podría ser que alguno que las lea halle algo que le agrade, y a los que no ahondaren tanto los deleite; y a este proposito dice Plinio que no hay libro, por malo que sea, que no tenga alguna cosa buena; mayormente que los gustos no son todos unos, mas lo que uno no come, otro se pierde por ello. Y así vemos cosas tenidas en poco de algunos, que de otros no lo son. $\mathrm{Y}$ esto, para ninguna cosa se debería romper ni echar a mal, si muy detestable no fuese, sino que a todos se comunicase, mayormente siendo sin perjuicio y pudiendo sacar della algún fruto.

Porque si así no fuese, muy pocos escribirían para uno solo, pues no se hace sin trabajo, y quieren, ya que lo pasan, ser recompensados, no con dineros, mas con que vean y lean sus obras, y si hay de que, se las alaben; y a este proposito dice Tulio: "La honra cría las artes."

[...] Y todo va desta manera: que confesando yo no ser más santo que mis vecinos, desta nonada, que en este grosero estilo escribo, no me pesara que hayan parte y se huelguen con ello todos los que en ella algún gusto hallaren, y vean que vive un hombre con tantas fortunas, peligros y adversidades [...] [grifo meu] (El Lazarillo de Tormes, 2005, p.23)

Ainda em El Lazarillo de Tormes, no tratado primeiro ${ }^{6}$, onde Lázaro (o experiente) apresenta Lazarillo (o menino inocente) e sua família, o narrador recorda um pensamento que teve quando via que seu irmão, que era negro, fugia do pai, tão negro quanto ele, chamando-o

\footnotetext{
${ }^{4}$ É o que acontece com o personagem de Jorge Luis Borges Funes, el memorioso que não suporta o peso de não esquecer. Funes é um uruguaio que não esquece nada do que vê e a caba morrendo de falta de ar. Funes, ao não esquecer, necessita de um dia interiro para recordar o dia anterior, se vê mais velho no espelho de um dia para o outro, pois sente como ninguém o passar do tempo. É como se a quantidade de recordações o fizessem explodir já que não existiria tempo necessário para rememorar o vivido.

${ }^{5}$ Para a noção de rastros ver GAGNEBIN, 2006.

${ }^{6}$ A obra El Lazarillo de Tormes se organiza por tratados, e em cada um destes, Lázaro assume um novo amo e uma nova condição rumo a sua suposta ascensão final. Temos um total de sete tratados.
} 
de $\operatorname{coco}^{7}$ pela cor de sua pele. Lázaro relata que, quando ainda era Lazarillo, pensou "Yo, aunque bien muchacho, noté aquella palabra de mi hermanico y dije entre mí: ‘Cuántos debe de haber en el mundo que huyen de otros porque no se ven a sí mismo!" (El Lazarillo de Tormes, 2005, p.26). Ora, este não é e não seria o raciocínio de um menino pequeno e inocente que não tinha consciência do mundo, já que até então nunca havia saído de Salamanca. Nota-se aí um processo de re-acomodação da memória. Lázaro relembra sua infância e re-significa sua lembrança com a experiência adulta. Não é Lazarillo que tem semelhante conceito sobre a consciência de cada um sobre si, mas Lázaro que crê haver pensado isso quando ainda era Lazarillo. Tal cena é importante na narrativa para convencer o leitor dos bons princípios que tinha Lazarillo antes de envolver-se com seus amos, porém tal cena soa falsa a uma leitura mais cuidadosa.

O mesmo ocorre em Dom Casmurro quando fala da infância de Bentinho e das atitudes de Capitu que, quando criança lhe causavam grande admiração, porém com o desenrolar da história e sua experiência passam a ser um argumento contra a menina e a favor do juízo primeiro feito com relação a ela por José Dias (olhos de ressaca). Diz Bento:

Como vês (ao leitor), Capitu, aos quatorze anos, tinha já idéias atrevidas, muito menos que outras que lhe vieram depois; mas eram só atrevidas em si, na prática faziam-se hábeis, sinuosas, surdas, e alcançavam o fim proposto, não de salto, mas aos saltinhos. (ASSIS, 1997, p.4)

Seria este o pensamento que tinha aos catorze anos? E mais: se estivesse tão convencido das falhas de caráter e da esperteza tremenda de Capitu, teria Bentinho se casado com ela? Provavelmente não, ou provavelmente Bentinho não era tão inocente e tão títere de Capitu como Dom Casmurro tenta convencer ao leitor, falando diretamente a ele.

Assim como fator culminante para estas re-acomodações, re-agrupações, resignificações feitas pela memória, entra em jogo o tempo. Como comentado acima, a história contada não é a de Lázaro de Tormes, mas a de Lazarillo de Tormes, isto é, a história narrada é de como Lazarillo, aquele menino pobre que nasce no rio Tormes, tornou-se o pregoeiro de vinhos Lázaro, que vive com a criada do arcipreste de San Salvador. Quem conta é Lázaro, quem nasce é Lazarillo. O mesmo ocorre na narrativa de Machado de Assis. Bento Santiago, o famoso Dom Casmurro, conta a história de Bentinho, o menino que fugia do seminário e que pensava encontrar a felicidade nos braços da ardilosa Capitulina. $\mathrm{O}$ afastamento temporal - Bento já é um senhor e Lázaro é um homem feito - faz com que haja uma consciência diferente dos fatos vividos, quer porque o narrador realmente veja com outros olhos, com os

\footnotetext{
${ }^{7}$ Equivalente ao bicho-papão em espanhol.
} 
olhos descompromissados aquilo que já passou e que não pode ser alterado, quer porque sabe que tem que voltar àquele passado com o compromisso de modificá-lo e assim re-significar ou alterar o seu presente, ou a forma, como ele ou os outros o vêem no presente. Neste ir e vir, entre passado e presente, se agregam à memória feiticeira, as impressões do presente, as necessidades que pedem o presente e a imaginação. A propósito desta relação Jeanne Marie Gagnebin retoma Walter Benjamin (“O narrador”) e fala da rememoração que consistiria nesta ligação entre passado e presente que se dá também pelo esquecimento e pelas brechas e brancos da memória. Diz Gagnebin:

[...] Tal rememoração implica uma certa ascese da atividade historiadora que, em vez de repetir aquilo de que se lembra, abre-se aos brancos, aos buracos, ao esquecido e recalcado, para dizer, com hesitações, solavancos, incompletude, aquilo que ainda não teve direito nem à lembrança nem às palavras. A rememoração também significa uma atenção precisa ao presente, em particular a estas estranhas ressurgências do passado no presente, pois não se trata somente de não esquecer do passado, mas também de agir sobre o presente. [grifo meu] (GAGNEBIN, 2006, p.55)

No caso de Dom Casmurro o próprio narrador deixa brechas ao leitor de que a traição de Capitu não é tão lógica e comprovada como já foi discutido tantas vezes, ainda que pense ou queira convencer-se do contrário. Em determinado trecho da obra Bento nota que a semelhança de Ezequiel e Escobar é intrigante e muito profunda:

Eu mesmo achava feio tal sestro. Alguns dos gestos já lhe iam ficando mais repetidos, como o das mãos e pés de Escobar; ultimamente, até apanhara o modo de voltar da cabeça deste, quando falava, e o de deixá-la cair, quando ria. (ASSIS, 1997, p.208)

Porém, em capítulos anteriores, ao visitar a casa de Sancha quando esta está doente, o pai da menina lhe faz notar a semelhança que a mãe de Sancha tem com Capitu:

[...] Gurgel, voltando-se para a parede da sala, onde pendia um retrato de moça, perguntou-me se Capitu era parecida com o retrato.

Um dos costumes da minha vida foi sempre concordar com a opinião do provável do meu interlocutor, desde que a matéria não me agrava, aborrece ou impõe. Antes de examinar se efetivamente Capitu era parecida com o retrato, fui respondendo que sim. Então ele disse que era o retrato da mulher dele, e que as pessoas que a conheceram diziam a mesma coisa. Também achava que as feições eram semelhantes, a testa principalmente e os olhos. Quanto o gênio, era um; pareciam irmãs.

- Finalmente, até a amizade que ela tem a Sanchinha; a mãe não era mais amiga dela... Na vida há dessas semelhanças assim esquisitas. (ASSIS, 1997, p.156)

Logo, estaria Dom Casmurro, já Casmurro, convencido da traição, após a morte de Capitu, de Ezequiel e de Escobar? Estaria Lázaro de Tormes convencido que leva uma vida honesta, de que sua mulher é também honesta e de que não o trai com o arcipreste? Certamente não, pois se estivessem certos tais narradores não necessitariam escrever e fazer públicas suas dúvidas e seus conflitos. Como já foi dito, narrar para ambos os narradores é 
uma espécie de redenção de seus crimes e de suas culpas. Lázaro necessita justificar sua vida para vuestra merced e para a sociedade e Dom Casmurro para ele mesmo e assim encontrarse. A memória de seres tão conflitados, que tentam demonstrar que não o são, é tão conflituosa como eles mesmos, feiticeira como bem diz Bento e como toda a feiticeira cheia de truques. O feitiço da transcodificação do fato em memória se dá como no processo de tradução (SÁEZ HERMOSILLA, 1994). Existe o fato (no caso da tradução a palavra) que é apreendido, desverbalizado e guardado no cérebro como idéia. Quando é contado novamente, o fato deve ser mais uma vez verbalizado. Nesta segunda verbalização, a palavra ouvida já não é a mesma que nos chegou aos ouvidos, mas um sinônimo que, juntando-se a outros sinônimos também guardados no cérebro, criam uma nova realidade que vale pelos fatos, mas que realmente não são os fatos vividos e sim os fatos vividos romanceados. Logo, cria-se a ficção como diz o escritor espanhol Jorge Semprún que trabalha com narrativas da memória:

Ahora bien, uma gran novela no puede contentarse com la transcripción de lo vivido, aunque esta trasncripción esté elaborada, depurada, porque lo vivido siempre formará una pantalla, obnubilando la invención de la realidad que es lo propio del arte de la novela. (SEMPRÚN, 1996, p.221)

Com vimos, a narração de ambas as histórias em questão se apóiam em pontos muito semelhantes. Um narrador que conta suas memórias (suas e não dos outros) e que busca através delas a sua absolvição. Para ter uma memória, é necessário o tempo, que faz com que o fato se transforme em memória do fato, e, claro, um fato conflitante a ser contado. Para fazer públicas as memórias, é necessário escolher o que contar e saber por que e como se deve contar. Em ambos os romances, os narradores partem de um estado de inocência. Lazarillo é o jovem pobre que aprende com o mal do mundo, e Dom Casmurro não deixa de ser o mesmo, já que é títere de quase todos os personagens até que toma consciência da suposta traição. Quanto a Lazarillo de Tormes, o personagem provoca em leitores menos avisados uma certa compaixão devido à falta de condições do personagem e sua humanidade, porém, Lazarillo não é um pícaro? E quem conta a história não é ele, Lázaro já adulto após ter aprendido a astúcia de seus amos? Será que Lázaro não é tão astuto a ponto de nos fazer acreditar na inocência, em sua inocência e na vileza dos outros personagens?

Dom Casmurro não provoca tanta compaixão, já que não é tão humano quanto Lazarillo parece ser, pelo contrário, quer se mostrar uma pessoa fria e conforme com seu destino. Porém, alguém que está conforme com seu destino necessita atar as duas pontas da vida através do exame do passado? Não defendo aqui uma possível cópia de Machado de Assis aos moldes do Lazarillo de Tormes, no entanto, parece-me que uma aproximação se faz 
bastante plausível e não duvido do flerte de Machado com a picaresca espanhola. Dom Casmurro, o futuro do inocente Bentinho, também aprendeu com a ardilosa Capitu, com Escobar e José Dias (bem como Lázaro de seus amos), senão não teria dado a reviravolta em sua vida. Será que não aprendeu tanto, a ponto de enganar-nos em sua narrativa tanto como o faz Lázaro? Não estaríamos diante de um novo pícaro que usa da memória e de possíveis testemunhos de outros personagens, que, como já dito vem à tona apenas pelas lentes de seus olhos, para convencer-nos de que não errou, ou melhor, para convencer-se e convencer-nos de que não errou? Nos preceitos da novela picaresca estão a narrativa contada em primeira pessoa, o uso da memória, um estado de inocência inicial, a aprendizagem e a aplicação do aprendido, ou seja, o uso da astúcia na vida prática. Nesta perspectiva, Dom Casmurro pode ser visto tão pícaro como Lazarillo e ainda um pícaro menos convincente já que, em Lazarillo, temos a tal humanidade do personagem.

Desta forma, creio que ambos os relatos de narradores-personagens ou Deus-mundo, como me permito chamar, não são, de nenhuma maneira, confiáveis, como menos confiável é a memória de ambos, tão etérea e divina como a ficção. O narrar absolve a memória e a transforma pela ação do tempo e pela ação do narrador. Ambos - tempo e narrador- têm necessidade, a mesma necessidade de contar e, para esta necessidade bem como para os narradores, não existe a palavra inocência.

\section{Referências}

ANÔNIMO. El Lazarillo de Tormes. Madri: LIBSA, 2005.

ASSIS, Joaquim Maria Machado de. Dom Casmurro. São Paulo: Klick, 1997.

BORGES, Jorge Luis. Ficciones. Barcelona: Planeta-Agostini, 1995.

GAGNEBIN, Jeanne Marie. Lembrar escrever esquecer. São Paulo: Editora 34, 2006.

RIEDEL, Dirce Côrtes. O Tempo no Romance Machadiano. Rio de Janeiro: Livraria São José, 1959.

SÁEZ HERMOSILLA, Teodoro. El sentido de la traducción (reflexión y crítica). Salamanca: Universidad de León/Ediciones Universidad de Salamanca, 1994.

SEMPRÚN, Jorge. Federico Sánchez se despide de ustedes. Barcelona: Fábula, 1996.

SCHÜLER, Donaldo. Formas da Narrativa II - Plenitude perdida. Porto Alegre: Movimento, 1978. 
VALVERDE, José Maria. Breve Historia de la Literatura Española. Madri: Guadarrama, 1969.

ZAMBRANO, María. Hacia un saber sobre el alma. 2.ed. Madri: Alianza, 1993.

ZAMORA VICENTE, Alonso. Qué es la novela picaresca. Alicante: Biblioteca Virtual Miguel de Cervantes, 2002. 